\title{
Effectiveness and Toxicity Screening of Various Absorption Enhancers Using Caco-2 Cell Monolayers
}

\author{
Ying-shu Quan, ${ }^{a}$ Koji Hattori, ${ }^{a}$ Ewa Lundborg, ${ }^{b}$ Takuya Fujita, ${ }^{a}$ Masahiro Murakami, ${ }^{a}$ \\ Shozo Muranishi, ${ }^{a}$ and Akira Yamamoto ${ }^{a, *}$ \\ Department of Biopharmaceutics, Kyoto Pharmaceutical University, 5 Nakauchi-cho, Misasagi, Yamashina-ku, Kyoto, \\ 607, Japan and Department of Pharmaceutics, Uppsala University, ${ }^{b}$ Uppsala, Sweden. \\ Received December 19, 1997; accepted Feburary 24, 1998
}

\begin{abstract}
We studied the enhancing and toxic effects of five different absorption enhancers on the transport of FITCdextran with an average molecular weight of 4000 (FD-4) across Caco-2 cell monolayers, and their enhancing effects were also compared with those in rat intestine. The enhancing and cytotoxic properties of these enhancers were characterized using the following tests: measurement of the permeability coefficients of FD-4 and the transepithelial electrical resistance (TEER) in Caco-2, the release of cytosolic lactate dehydrogenase (LDH) and intracellular mitochondrial dehydrogenase (MDH) activity. All the absorption enhancers increased the permeability of FD-4 across Caco-2 cell monolayers and a good relationship was observed between the enhancement and their toxic effects. However, EDTA and Na-Cap were effective for improving the transport of FD-4 across Caco-2 cells without serious cytotoxicity. At concentrations with low cytotoxicity, various absorption enhancers exihibited reversible effects on the TEER values in Caco-2 cell monolayers, except for $50 \mathrm{mM}$ sodium salicylate (Na-Sal). Moreover, we obtained a good correlation between the enhancement of these enhancers in Caco-2 cell monolayers and in rat large intestine. This finding indicated that the effectiveness of absorption enhancers in the Caco-2 monolayer system was similar to an in vivo rat system. Therefore, the screening system using Caco-2 cell monolayers is useful for examining the effectiveness and toxicity of absorption enhancers.
\end{abstract}

Key words absorption enhancer; Caco-2; in vitro-in vivo correlation

Many water soluble macromolecular drugs, such as peptides and proteins, cannot cross into the intestinal mucosa due to their hydrophilicity and molecular size. Improvement of the intestinal uptake of these drugs is an important issue that has recently been researched by many groups. Of the many approaches, one way to increase the intestinal absorption of macromolecular drugs is with the co-administration of absorption enhancers, including surfactants, bile salts, chelating agents and fatty acids. ${ }^{1,2)}$ However, the practical use of these adjuvants is limited because they cause damage and irritation in the intestinal mucosal membrane. ${ }^{3,4)}$ An ideal absorption enhancer would improve the intestinal absorption of drugs without severe membrane damage or local irritation in their presence.

Recently, a human intestinal adenocarcinoma, Caco-2 cells, has been used in the intestinal models for drug absorption studies. ${ }^{5-8)}$ However, few studies have been performed to examine the relationship between the effectiveness of absorption enhancers and their toxicity using Caco-2 cells. Moreover, the correlation between the effectiveness of absorption enhancers in the Caco-2 cell model and animal experiment models has not been fully elucidated. If we have a good correlation between the Caco-2 model and animal experiment models regarding the enhancing effect of absorption enhancers, we can estimate the effectiveness of various absorption enhancers using Caco-2 cells.

In this study, FITC-dextran 4000 (FD-4) was chosen as a model macromolecular compound, and a variety of absorption enhancers, such as $n$-lauryl- $\beta$-D-maltopyranoside (LM), sodium glycocholate $(\mathrm{Na}-\mathrm{GC})$, sodium salicylate $(\mathrm{Na}-\mathrm{Sal})$, disodium EDTA (EDTA), and sodium caprate (Na-Cap) were used to compare their enhancing and toxic effects and to screen for useful enhancers using Caco-2 cell monolayers. In addition, we compared the enhancing effects of these en-

* To whom correspondence should be addressed. hancers in Caco-2 cell monolayers with those in rat intestine.

\section{MATERIALS AND METHODS}

Materials FD-4 and 3-(4,5-dimethylthiazol-2-yl)-2,5dipheyl tetrazolium bromide (MTT) were obtained from Sigma Chemical Co. (St. Louis, MO, U.S.A.). The LDH-kit was purchased from Wako Pure Chemical Industries (Osaka, Japan). All other chemicals were of analytical grade and were used without further purification. Transwell polycarbonate inserts were obtained from Costar (Cambridge, MA, U.S.A.).

Cell Cultures The human colon adenocarcinoma cell line Caco-2 was kindly provided by Dr. Kato, Eisai Co., Tsukuba, Japan. Caco-2 cells were routinely maintained in Dulbecco's modified Eagle's medium containing $10 \%$ fetal bovine serum, $1 \%$ non-essential amino acids, $1 \%$ L-glutamine, $100 \mathrm{U} / \mathrm{ml}$ penicillin $\mathrm{G}$ and $100 \mu \mathrm{g} / \mathrm{ml}$ streptomycin in a humidified $5 \% \mathrm{CO}_{2}-95 \%$ atomosphere at $37{ }^{\circ} \mathrm{C}$. Caco-2 cells were seeded onto polycarbonate filters for transport studies and were grown for $18-28 \mathrm{~d}$. The passage number of Caco2 cells was between $67-77$ in this study.

Transport Studies The confluent monolayers were washed three times with Hanks balanced salt solution (HBSS) prior to adding the HBSS buffer containing $10 \mu \mathrm{M}$ of FD-4. The experiment was performed at $37^{\circ} \mathrm{C}$ for $3 \mathrm{~h}$. After the addition of FD-4 solution to the apical side, a $100 \mu 1$ aliquot of samlpe was withdrawn from the basolateral side at appropriate time intervals. Control experiments were carried out using a polycarbonate filter alone without cell monolayers to measure the permeability of the drug across polycarbonate filters.

The amount of FD-4 was determined with a fluorescence spectrophotometer using excitation and emission wave-

(C) 1998 Pharmaceutical Society of Japan 
lengths of 495 and $512 \mathrm{~nm}$, respectively. The apparent permeability coefficient $\left(P_{\text {app }}\right)$ was determined according to the following equation:

$$
P_{\text {app }}=d X_{\mathrm{R}} / d t / A \cdot C_{\mathrm{o}}
$$

where $X_{\mathrm{R}}$ is the amount of FD-4 in the basolateral side, $C_{\mathrm{o}}$ is the initial concentration in the apical chamber, and $A$ is the surface area of the porous membrane $\left(1.13 \mathrm{~cm}^{2}\right)$.

The permeability coefficients across the monolayers alone $\left(P_{\text {cell }}\right)$ were calculated from the relationship:

$$
1 / P_{\text {cell }}=1 / P_{\text {app }}-1 / P_{\mathrm{m}}
$$

where $P_{\mathrm{m}}$ is the permeability coefficient across the filter support alone.

Determination of $\mathbf{L D H} \mathrm{LDH}$ is a cytosolic enzyme which is recovered from the extracellular compartment following membrane disruption. The effects of enhancers on $\mathrm{LDH}$ release in Caco-2 cells were determined by the method of Choksakulnimitr et al. ${ }^{9)}$ After the transport experiment, the solution collected from the apical side of each well was centrifuged and the supernatant was measured for released LDH activity $\left(\mathrm{LDH}_{\text {release }}\right)$. The cell precipitate and the monolayers left on the filters were solubilized with $1 \%$ Triton $X$ 100 , and the $\mathrm{LDH}$ activities $\left(L D H_{\text {detached cell }}\right.$ and $\left.L D H_{\text {cell }}\right)$ were measured, respectively. The $\mathrm{LDH}$ activity was determined with an LDH-kit. The percentage of LDH released was calculated by:

$$
\% L D H_{\text {release }}=L D H_{\text {release }} /\left(L D H_{\text {release }}+L D H_{\text {detached cell }}+L D H_{\text {cell }}\right) \times 100
$$

All results were expressed as the mean \pm S.E. of a specific percentage of $\mathrm{LDH}$ release which was obtained by subtracting the control value.

Determination of MDH The intracellular MDH activity was determined by the MTT method. ${ }^{10,11)}$ Briefly, MTT is a tetrazolium salt cleaved by $\mathrm{MDH}$ in living cells to a darkblue product. Cells were seeded in 96-well culture dishes at a density of $2.5 \times 10^{5}$ cells $/ \mathrm{cm}^{2}$ and cultivated under normal conditions for $21-28 \mathrm{~d}$. Afterwards, the cells were incubated for $3 \mathrm{~h}$ with each enhancer solution, rinsed with HBSS and incubated in a medium containing $0.5 \mathrm{mg} / \mathrm{ml}$ MTT for another $4 \mathrm{~h}$. The MTT solution was removed, the formed formazan crystals were dissolved with DMSO, and the color intensity was determined with a multiwell scanning spectrophotometer at a wavelength of $540 \mathrm{~nm}$.

Reversibility Studies The recovery of the monolayers after exposure to the absorption enhancers was studied by measuring the transepithelial electrical resistance (TEER) values in Caco- 2 monolayers. Initially, the monolayers were incubated with various enhancer solutions for $3 \mathrm{~h}$ and washed with HBSS. Afterwards, fresh culture medium was added to both sides of the monolayers, followed by further cultivation under normal conditions. At different time points the filters were washed with HBSS, TEER was determined in HBSS, and the monolayers were returned to the cell culture medium again. The TEER value in the control experiment was $268 \pm$ $2 \Omega \cdot \mathrm{cm}^{2}$ and was almost constant during the experiment. The initial values were set to $100 \%$ and the TEER values at different points in the presence of absorption enhancers were normalized by dividing them by the corresponding control values.

Perfusion Studies In situ perfusion studies were per- formed in rats using a single-pass perfusion technique. ${ }^{12)}$ Male Wistar rats weighing $220-250 \mathrm{~g}$ were anesthetized with sodium pentobarbital ( $32 \mathrm{mg} / \mathrm{kg}$ body weight) by intraperitoneal injection. The animals were fasted for about $18 \mathrm{~h}$ prior to the experiments but were allowed water ad libitum. After the animals had been secured on the animal board that was maitained at $37^{\circ} \mathrm{C}$, the large intestinal segments were cannulated at the proximal ends of the large intestines and anuses following a midline longitudinal incision. Perfusate containing $10 \mu \mathrm{M}$ of FD-4 was infused continuously at a rate of $16 \mathrm{ml} / \mathrm{h}$ through the segments. Steady state was achieved in approximately $30 \mathrm{~min}$, after which five samples were taken at $10 \mathrm{~min}$ intervals. In sample analysis, the plug flow model was applied to determine the intestinal permeability. ${ }^{13)}$ The effective permeability $\left(P_{\text {eff }}\right)$ was calculated using the following equation:

$$
P_{\text {eff }}=Q \cdot\left(1-C_{\text {out }} / C_{\text {in }}\right) / 2 \pi R L
$$

where $Q$ is the flow rate, $C_{\text {in }}$ is the inlet concentration, $C_{\text {out }}$ is the exit concentration, $R$ is the radius of the intestine and $L$ is the perfused intestinal length.

Statistical Analysis Results are expressed as the mean \pm S.E. and statistical significance was performed using a Student's $t$-test.

\section{RESULTS}

Effects of Various Absorption Enhancers on the Transport of FD-4 across Caco-2 Cell Monolayers Figure 1 shows the permeability of FD-4 across Caco- 2 cell monolayers in the presence of various absorption enhancers. $P_{\text {cell }}$ values were used for evaluating the enhancing effects of various absorption enhancers. All the absorption enhancers increased the permeability of FD-4 across Caco- 2 cell monolayers. With LM and Na-Cap, a dose-dependent increase in the permeability of FD-4 across Caco- 2 cell monolayers was observed. LM had a marked enhancing effect, even at a low concentration. The $P_{\text {cell }}$ value of FD-4 with $200 \mu \mathrm{M} \mathrm{LM}$ was $1.76 \times 10^{-6} \mathrm{~cm} / \mathrm{s}, 2.5$-fold higher than the control, while in the presence of $1 \mathrm{mM} \mathrm{LM}$ it was $5.40 \times 10^{-6} \mathrm{~cm} / \mathrm{s}, 7.7$-fold higher than the control. On the other hand, $\mathrm{Na}-\mathrm{Sal}$ did not

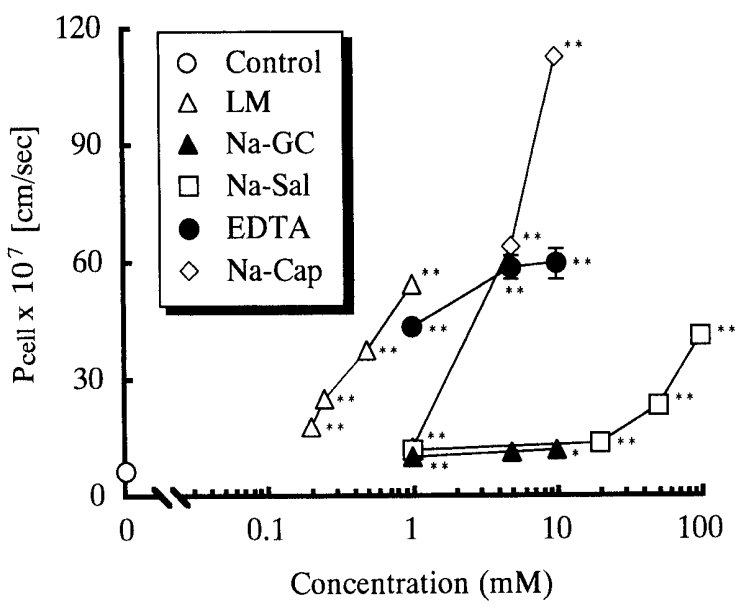

Fig. 1. Effects of Various Absorption Enhancers on the Permeability of FD-4 Across Caco-2 Cell Monolayers

Each value represents the mean \pm S.E. of at least three experiments. $* * ; p<0.01$, $* ; p<0.05$, compared with the control. 


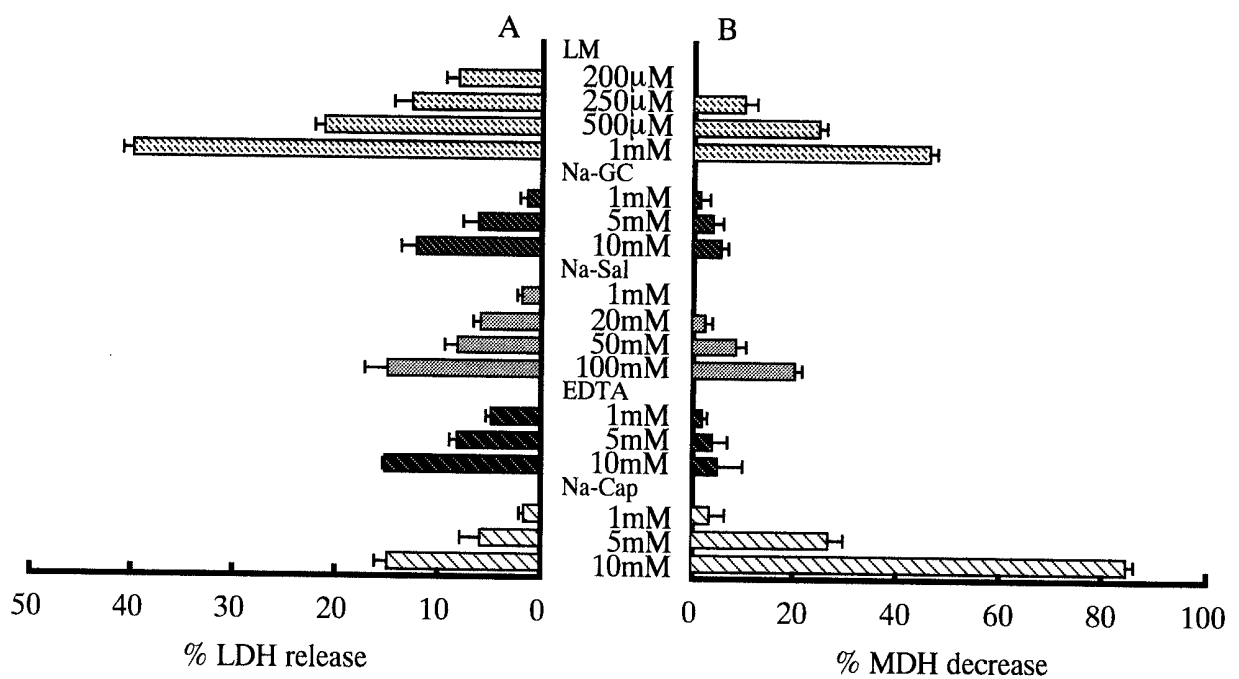

Fig. 2. Toxic Effects of Various Absorption Enhancers in Caco-2 Cells after $3 \mathrm{~h}$ Incubation at $37^{\circ} \mathrm{C}$

Each value represents the mean \pm S.E. of at least three experiments. A: $L D H$ release, B: MDH decrease.

show a high enhancing effect at concentrations lower than $20 \mathrm{mM}$, whereas at high concentrations $(>50 \mathrm{mM})$, the permeation of FD-4 was increased more than 3.2-fold in comparison to the control. These findings suggested that higher concentrations of $\mathrm{Na}$-Sal were needed to improve the permeability of FD-4 across Caco-2 cell monolayers. EDTA significantly increased the permeation of FD-4, even at $1 \mathrm{mM}$ (6.2fold higher than the control), and at concentrations higher than $5 \mathrm{mM}$ its enhancement effect reached a plateau. However, Na-GC exerted a limited enhancing effect at concentrations of $1-10 \mathrm{mM}$.

Effects of Various Absorption Enhancers on the Cytotoxicity in Caco-2 Cells LDH release and intracellular MDH activity were measured as a marker of apical membrane damage and intracellular toxicity in this experiment. As shown in Fig. 2, all the absorption enhancers increased LDH release and decreased MDH activity in a dose-dependent manner. Of these absorption enhancers, LM showed marked effects in both LDH release and intracellular MDH activity. In the presence of Na-Cap, the decrease in MDH activity was more clearly observed than the increase in LDH release. In contrast, no significant decrease in MDH activity was observed in the presence of EDTA. These findings suggested that these absorption enhancers have different patterns of cytotoxicity.

The time-dependent effects of the enhancers on LDH release and the permeability of FD-4 were also examined (Fig. 3). LM exerted time-dependent effects both on LDH release and the permeation of FD-4, whereas EDTA only had timedependent effects on the permeation of FD-4. We found no significant increase in LDH release up to $120 \mathrm{~min}$ in the presence of EDTA.

Relationship between the Enhancement and the Cytotoxicity of Various Absorption Enhancers To select a useful absorption enhancer, we need to find an effective and less toxic enhancer. In this study, therefore, we examined the relationship between the enhancement effect of absorption enhancers and their cytotoxicity in Caco-2 cells (Fig. 4). Overall, there exists a relationship between these two parameters. That is, most of the enhancers which have high $P_{\text {cell }}$ values also have high $\mathrm{LDH}$ release \% values and low intra-
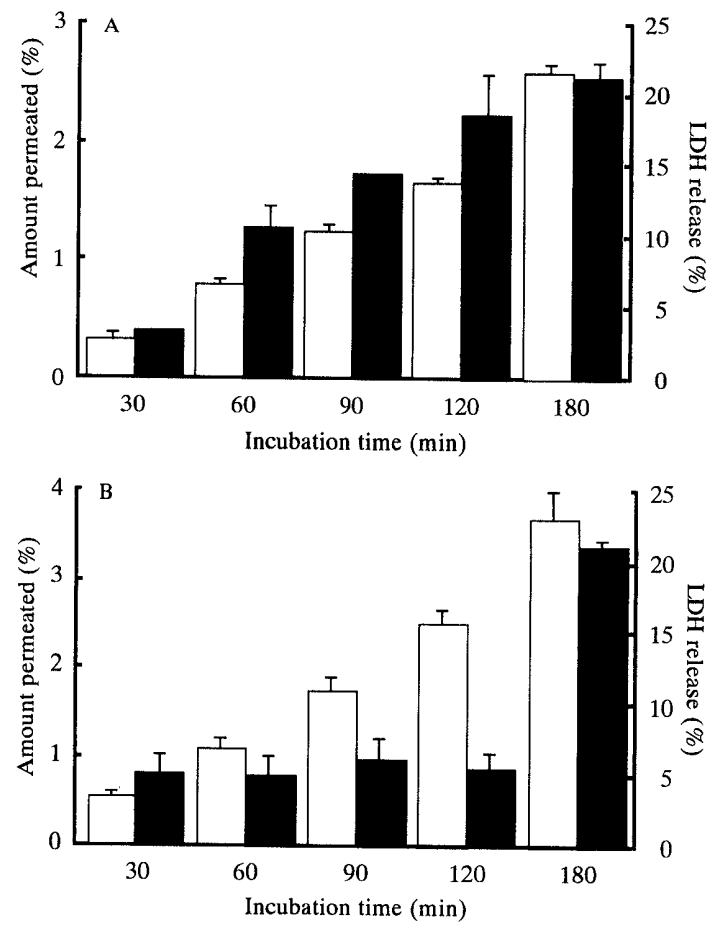

Fig. 3. Time-Dependent Effects of Enhancers (A; $500 \mu \mathrm{M}$ LM, B; $10 \mu \mathrm{M}$ EDTA) on the Permeability of FD-4 (Open Bar) and the LDH Release (Filled Bar) in Caco-2 Cells

Each value represents the mean \pm S.E. of at least three experiments.

cellular MDH \% values. LM improved the transport of FD-4 across Caco- 2 cells, but it also had a high toxic effect, as indicated in the $\mathrm{LDH}$ release \% and the intracellular $\mathrm{MDH} \%$ values. However, some absorption enhancers, including EDTA and Na-Cap, were effective for improving the transport of FD-4 across Caco-2 cells without serious cytotoxicity.

Reversibility of Monolayers Treated with Enhancers The reversibility of the monolayers was studied by measuring the TEER in the presence of various absorption enhancers at concentrations with low cytotoxicity (Fig. 5). The reversible processes of TEER values with $\mathrm{Na}-\mathrm{GC}$, Na-Cap and EDTA could be divided into two phases. One was the initial rapid phase, which lasted for approximately $1 \mathrm{~h}$, and another was 

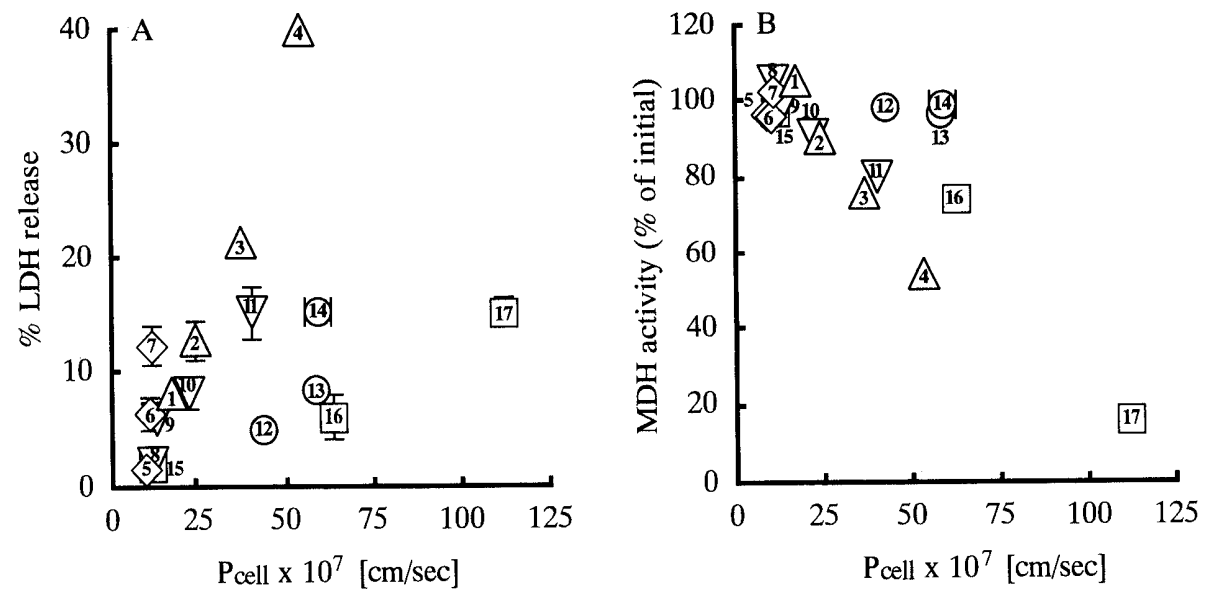

Fig. 4. Relationship between the Effects of Various Absorption Enhancers on the Permeability of FD-4 and Their Toxic Effects (A: LDH Release, B: MDH Activity) in Caco-2 Cell Monolayers

Each point represents the mean \pm S.E. of at least three experiments. Key: $1-4,0.2,0.25,0.5,1 \mathrm{mM} \mathrm{LM}(\triangle) ; 5-7,1,5,10 \mathrm{mM}$ Na-GC $(\diamond) ; 8-11,1,20,50,100 \mathrm{mM} \mathrm{Na-Sal}$ $(\nabla) ; 12-14,1,5,10 \mathrm{mM}$ EDTA $(\bigcirc) ; 15-17,1,5,10 \mathrm{mM} \mathrm{Na}-\mathrm{Cap}(\square)$.
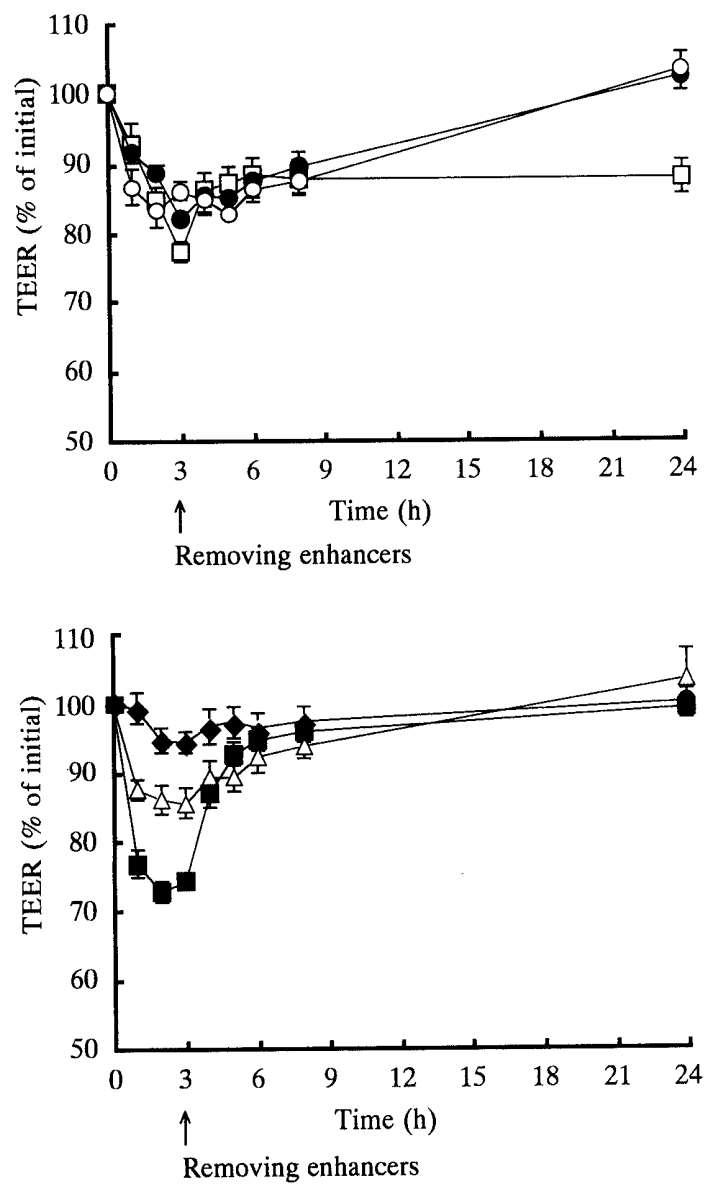

Fig. 5. Reversibility of the TEER Values Decreased by Absorption Enhancers at Concentrations with Low Cytotoxicity

The TEER value of the control was $268 \pm 2 \Omega \cdot \mathrm{cm}^{2}(n=48)$. The initial values were set to $100 \%$ and the TEER values at different points in the presence of absorption enhancers were normalized by dividing them with the corresponding control values. Each point represents the mean \pm S.E. of at least three experiments. Key: $\bigcirc, 200 \mu \mathrm{M} \mathrm{LM} ;$ $20 \mathrm{mM}$ Na-Sal; $\square, 50 \mathrm{mM} \mathrm{Na}$-Sal; $\mathbf{E}, 1 \mathrm{mM}$ EDTA; $\triangle, 1 \mathrm{mM} \mathrm{Na-Cap} ; \bullet, 5 \mathrm{mM} \mathrm{Na}$ GC.

the slower recovery phase, during which the initial level was recovered within $20 \mathrm{~h}$. Except for $50 \mathrm{mM} \mathrm{Na-Sal,} \mathrm{all} \mathrm{other}$ enhancers had reversible effects on monolayers.

In Vitro-in Vivo Correlation between Absorption En-

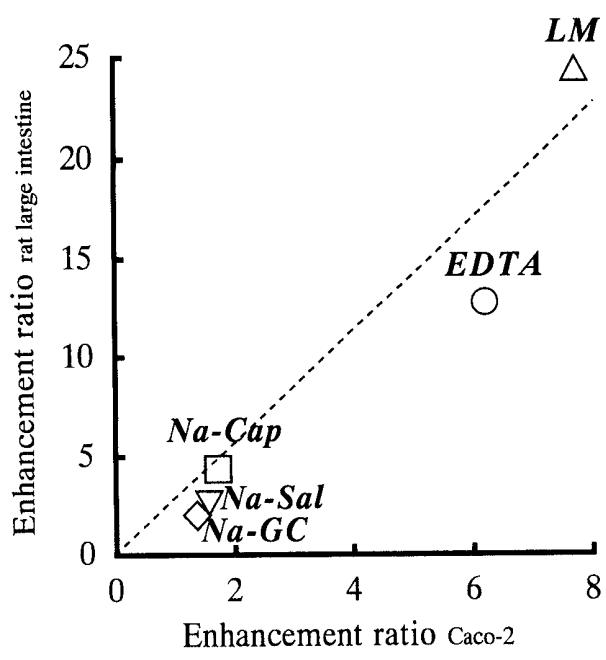

Fig. 6. Relationship between the Enhancement Ratio of Various Absorption Enhancers in Caco-2 Cell Monolayers and in Rat Large Intestine

The enhancement ratio was calculated by the following equation.

the enhancement ratio $=\frac{\text { permeability coefficient (enhancer) }}{\text { permeability coefficient (control) }}$

where permeability coefficient (enhancer) represents the permeability coefficient of FD-4 in the presence of absorption enhancers and permeability coefficient (control) represents the permeability coefficient of FD-4 in the control experiment.

hancement Effect by Aborption Enhancers We compared the effectiveness of absorption enhancers on the large intestinal absorption of FD-4 by an in vivo absorption study with that on in vitro Caco-2 cell monolayers. As shown in Fig. 6, a linear relationship was obtained between the enhancement ratio of various absorption enhancers in Caco-2 cell monolayers and in rat large intestine $(r=0.922)$.

\section{DISCUSSION}

In the present study, we found that LM improved the permeation of FD-4 across Caco- 2 cells in a dose-dependent manner, and the permeation of FD-4 was improved even in the presence of low concentration of LM $(200 \mu \mathrm{M})$. Murakami et al. reported that LM improved the rectal absorption of 6-carboxyfluorescein in a dose-dependent manner. ${ }^{14)}$ 
Therefore, our results in Caco-2 cells were consistent with the previous findings in the rectal absorption studies. Moreover, a dose-dependent increase in the permeability of FD-4 across Caco-2 cells was observed in the presence of Na-Cap. Lindmark et al. demonstrated that Na-Cap enhanced the permeability of $\left[{ }^{14} \mathrm{C}\right]$ mannitol across Caco- 2 cells in a dose-dependent manner, ${ }^{7)}$ which fairly concurs with our present finding.

Although EDTA significantly increased the permeability of FD-4 at $1 \mathrm{mM}$, it did not show a concentration-dependent effect at concentrations higher than $5 \mathrm{mM}$. In this experiment, $\mathrm{Ca}^{2+}$ and $\mathrm{Mg}^{2+}$ were excluded from the apical buffer solution to inhibit the precipitation of EDTA in the presence of $\mathrm{Ca}^{2+}$ and $\mathrm{Mg}^{2+}$. It has been reported that the normal cellular $\mathrm{Ca}^{2+}$ level is maintained by the basolateral buffer solution, and the paracellular route would not be affected by removing $\mathrm{Ca}^{2+}$ from the apical side. ${ }^{15)}$ Hence, our result may explain the saturable chelating effects of EDTA at higher concentrations due to a limited $\mathrm{Ca}^{2+}$ concentration.

We also found that a higher concentration of $\mathrm{Na}-\mathrm{Sal}$ was needed to improve the permeability of FD-4 across Caco-2 cells. In the previous report, Nishihata et al. indicated that $\mathrm{Na}$-Sal and 5-methoxysalicylate at a high dose $(15 \mathrm{mg} / 0.2 \mathrm{ml})$ improved the intestinal absorption of insulin and other peptides. ${ }^{16)}$ Therefore, the present finding agrees with the previous finding. On the other hand, we observed that Na-GC did not improve the permeability of FD- 4 across Caco- 2 cells, although this bile salt is effective for improving the intestinal absorption of poorly absorbable drugs including peptides, by in vivo intestinal absorption studies. ${ }^{17)}$ It was reported that $\mathrm{Na}-\mathrm{GC}$ enhanced the permeability by removing the epithelial cells, which constitute a major permeability barrier. ${ }^{18)}$ In addition, Gordon et al. suggested that bile salts interact with cell membranes to form a reverse micelle which acts as a channel to increase permeation by the test compounds. ${ }^{19)}$ Further, it was demonstrated that Na-GC may promote insulin transport across the nasal mucosa by retarding insulin degradation by leucine aminopeptidase, a proteolytic enzyme. $^{20)}$ The enhancing effect of Na-GC by in vivo studies may be related to these mechanisms. In addition, the different results between intact intestines and Caco- 2 cells may be partly explained by their different structure and by the different sensitivity of Na-GC to these systems.

Recently, the toxicity of absorption enhancers has been assessed by various methods, including the measurement of hemolysis, protein and phospholipid release and morphological observation. ${ }^{2)}$ Hemolysis is an easy way to assess local toxicity. However, the results obtained by this method sometimes might not extrapolate directly to the mucosal cells exposed to the enhancers. Although morphological observation has also been widely used to assess local toxicity, it cannot be used for quantitative assessment of local toxicity to the mucosal membrane. On the other hand, biological markers such as protein and phospholipid release and the release of marker enzymes are suitable for the quantitive analysis of local toxicity to the mucosal membrane. In this study, therefore, we examined the cytotoxicity of absorption enhancers, including membrane damage and intracellular toxicity, by measuring the LDH release and intracellular MDH activity.

We found that the cytotoxicity of LM was enhanced as its concentration increased in Caco- 2 cells. This finding sug- gested that LM might be a useful enhancer at low concentrations, although high concentrations of LM cannot be used in clinical application due to its high toxicity. This finding is similar to our previous results obtained from rat intestine. ${ }^{14)}$ On the other hand, the toxic effects of $\mathrm{Na}$-Cap were more remarkably observed in the MDH decrease studies than those in the LDH release studies. This finding indicates that the toxic effect of Na-Cap may be more clearly observed in the intracellular regions than in the membrane. We demonstrated that the MDH activity was not decreased significantly by the addition of EDTA. It is known that EDTA has an enhancing effect by chelating $\mathrm{Ca}^{2+}$ to open the tight junctions of the epithelium. $^{21)}$ Therefore, this enhancing effect of EDTA via a paracellular route cannot be evaluated by the release of LDH and a decrease of $\mathrm{MDH}$ activities, although EDTA may change the structure of the epithelium, which is related to the paracellular route.

In the time-course studies of the efficacy and safety of absorption enhancers, LM increased the permeability of FD-4 and the release of $\mathrm{LDH}$ in a time-dependent manner. In contrast, EDTA did not increase the LDH release up to $120 \mathrm{~min}$. The different results of these two enhancers can be explained by their different absorption enhancing mechanisms. LM, which is known to be a non-ionic surfactant, has recently been found to lower surface tension and to have absorptionenhancing activity in the gastrointestinal tract. ${ }^{14)}$ Our recent studies also indicated that the absorption enhancing mechanism of LM may be related to the intact $\mathrm{SH}$ group of the membrane-associated protein simillar to some unsaturated fatty acids. ${ }^{14,22)}$ On the other hand, as described above, EDTA has an enhancing effect via a paracellular route by chelating $\mathrm{Ca}^{2+}$ to open the tight junctions of the epithelium. The low interaction of EDTA with the membrane may be related to the low toxic effects in our cytotoxicity studies, as evaluated by the release of $\mathrm{LDH}$. The reason for the significant increase in LDH release at $180 \mathrm{~min}$ in the presence of EDTA was observed is unclear. However, Yamashita et al. reported that a higher concentration of EDTA may act on the transcellular route as well as the paracellular route by the analysis of voltage-clamp experiments. ${ }^{23)}$ Therefore, it may be speculated that long term exposure of EDTA may also disrupt the apical membrane of Caco-2 cells, thereby increasing the LDH release.

We found an almost linear relationship between the absorption enhancing effects of various absorption enhancers and their cytotoxicity in Caco- 2 cells. However, of these enhancers, Na-Cap and EDTA seem to be useful enhancers, since they have high absorption enhancing effects without serious cytotoxic effects. It was reported that $\mathrm{Na}-\mathrm{Cap}$ increased the permeability of rat intestinal brush border membrane through perturbation of the membrane, and promoted the intestinal absorption of poorly absorbable drugs. ${ }^{24)}$ Moreover, this fatty acid is used as an absorption enhancer for an ampicillin suppository in clinical application because of its low toxicity. Therefore, our results concur with those findings.

In this study, various absorption enhancers decreased the TEER values, as shown in Fig. 5. This result indicates that these absorption enhancers might open the tight junctions of the epithelium. In addition, there are two phases in the reversible process of TEER values which are decreased by absorption enhancers. Anderberg et al. reported that Na-Cap 
Table 1. Permeability Coefficients of FD-4 Obtained in Caco-2 Cells and in Rat Large Intestine

\begin{tabular}{lcc}
\hline \hline & $\begin{array}{c}\text { Caco-2 } \\
P_{\text {cell }} \times 10^{6}[\mathrm{~cm} / \mathrm{s}]^{a)}\end{array}$ & $\begin{array}{c}\text { Rat large intestine } \\
P_{\text {eff }} \times 10^{5}[\mathrm{~cm} / \mathrm{s}]^{b)}\end{array}$ \\
\hline Control & $0.71 \pm 0.56$ & $0.36 \pm 0.05$ \\
LM & $5.40 \pm 0.13$ & $8.83 \pm 0.27$ \\
Na-GC & $0.96 \pm 0.03$ & $0.81 \pm 0.06$ \\
Na-Sal & $1.15 \pm 0.03$ & $1.04 \pm 0.43$ \\
EDTA & $4.34 \pm 0.16$ & $4.60 \pm 0.16$ \\
Na-Cap & $1.20 \pm 0.10$ & $1.60 \pm 0.06$ \\
\hline
\end{tabular}

Each value represents the mean \pm S.E. of at least three experiments. a) All enhancers are used at the concentration of $1 \mathrm{mM}$ in Caco-2 cells. b) All enhancers are used at the concentration of $20 \mathrm{mM}$ in rat large intestine.

enhanced the transport of mannitol across Caco- 2 cell monolayers in a reversible manner. ${ }^{15)}$ They also demonstrated that the recovery of monolayers after exposure with Na-Cap could be divided into two phases, one initial rapid phase and a second slower recovery phase, ${ }^{15)}$ which is similar to our present finding. Furthermore, Na-Sal had an irreversible effect on the TEER values in Caco- 2 cells. This irreversible effect of Na-Sal may be attributed to non-specific epithelial damage, as suggested by Hurni et al. ${ }^{25)}$

We compared the effectiveness of absorption enhancers by in vivo absorption studies with that by in vitro Caco- 2 cell monolayers. As shown in Table 1, the permeability of FD-4 in the presence or absence of various absorption enhancers in Caco-2 cell monolayers was approximately 10 -fold lower than the values in rat intestine. Tanaka et al. reported that the high resistance and low permeability of Caco- 2 cell monolayers compared with rat intestinal membrane may be due to structural differences between the membranes, rather than a difference in the tightness of the junction. ${ }^{26)}$ That is, they reported that the number of tight junctions per unit area is larger in the jejunum than in Caco-2 cell monolayers. ${ }^{25)}$ Therefore, the low permeability characteristics of Caco-2 cells may be due to this small number of tight junctions per unit area. Furthermore, we obtained a linear relationship between the enhancement ratio of various absorption enhancers in Caco-2 cell monolayers and in rat large intestine (Fig. 6). This indicates that the effectiveness of absorption enhancers was similar in the two systems. In our preliminary experiment, we also examined the correlation between the enhancement ratio of various absorption enhancers in Caco- 2 cell monolayers and in rat small intestine, since Caco-2 is usually used as a model of the small intestine for absorption studies. We found a good correlation between these two systems, although the correlation coefficient between Caco-2 cells and the large intestine was better than that between Caco- 2 and the small intestine. This result may be attributed to the origin of Caco- 2 cells, since Caco-2 cells were derived from human colon carcinoma cells.
In conclusion, we demonstrated that there exists a linear relationship between the absorption enhancing effects of various absorption enhancers and their cytotoxicity in Caco-2 cell monolayers. Some of these absorption enhancers may be useful because of their high absorption enhancing activities and relatively low cytotoxicity. Furthermore, we also observed a good relationship between the enhancement ratios of various absorption enhancers in Caco- 2 cells and those in rat large intestine. Therefore, Caco-2 cells may be a useful tool for examining the effectiveness of absorption enhancers.

\section{REFERENCES}

1) Muranishi S., Crit. Rev. Ther. Drug Carrier Syst., 7, 1-33 (1990).

2) Lee V. H. L., Yamamoto A., Kompella U. B., Crit. Rev. Ther. Drug Carrier Syst., 8, 91-192 (1991).

3) Anderberg E. K., Artursson P., J. Pharm. Sci., 82, 392-398 (1993)

4) Schasteen C. S., Donovan M. G., Cogburn J. N., J. Control. Rel., 21, 49-62 (1992).

5) Artursson P., Karlsson J., Biochem. Biophys. Res. Commun., 175, $880-885$ (1991).

6) Audus K. L., Bartel R. L., Hidalgo I. J., Borchardt R. T., Pharm. Res., 7, 435-451 (1990).

7) Lindmark T., Nikkila T., Artursson P., J. Pharmacol. Exp. Ther., 275, 958-964 (1995).

8) Fujita T., Kawahara I., Yamamoto M., Yamamoto A., Muranishi S., Pharm. Sci., 1, 231-234 (1995).

9) Choksakulnimitr S., Masuda S., Tokuda H., Takakura Y., Hashida M., J. Control. Rel., 34, 233-241 (1995).

10) Mosmann T., J. Immunol. Method, 65, 55-63 (1983).

11) Boulenc X., Breul T., Gautier J. C., Saudemon P., Joyeux H., Roques C., Berger Y., Fabre G., J. Pharmacol. Exp. Ther., 123, 71-83 (1995).

12) Johnson D. A., Amidon G. L., J. Theor. Biol., 131, 93-106 (1988).

13) Amidon G. L., Kou J., Elliott R. L., Lightfoot E. N., J. Pharm. Sci., 69, 1369-1373 (1980).

14) Murakami M., Kusanoi Y., Takada K., Muranishi S., Int. J. Pharm., 79, 159-169 (1992).

15) Anderberg E. K., Lindmark T., Artursson P., Pharm. Res., 10, 857864 (1993).

16) Nishihata T., Rytting J. H., Kamada A., Higuchi T., Diabetes, 30, 1065-1067 (1981).

17) Kakemi K., Sezaki H., Konishi R., Kimura T., Murakami M., Chem. Pharm. Bull. 18, 275-280 (1970).

18) Hersey S. J., Jackson R. T., J. Pharm. Sci., 76, 876-879 (1987).

19) Gordon G. S., Moses A. C., Silver R. D., Filter J. S., Carey M. C., Proc. Natl. Acad. Sci. U.S.A., 82, 7419-7423 (1985).

20) Hirai S., Yasiki T., Mima H., Int. J. Pharm., 9, 173-184 (1981b).

21) Cassidy M. M., Tidball C. S., J. Cell Biol., 32, 685-697 (1967).

22) Ohtani T., Murakami M., Yamamoto A., Takada K., Muranishi S., Int. J. Pharm., 77, 141-150 (1991).

23) Yamashita S., Saitoh H., Nakanishi K., Masada M., Nadai T., Kimura T., J. Pharm. Pharmacol., 37, 512-513 (1985).

24) Kajii H., Horie T., Hayashi M., Awazu S., J. Pharm. Sci., 77, 390 392 (1988).

25) Hurni M. A., Noach B. J., Bloom-Roosemalen M. C., Deboer A. G., Nagelkerke J. F., Breimer D. D., J. Pharmacol. Exp. Ther., 267, 942950 (1993).

26) Tanaka Y., Taki Y., Sakane T., Nadai T., Sezaki H., Yamashita S., Pharm. Res., 12, 523-528 (1995). 